\title{
IMMUNOHISTOCHEMICAL DETECTION OF INTERMEDIATE FILAMENT NESTIN
}

\author{
Jaroslav Mokrý, Stanislav Němeček \\ Department of Histology and Embryology, Charles University, Faculty of Medicine, Hradec Králové; \\ (Head: prof. MUDr. S. Němeček, DrSc.)
}

Summary: Using Rat-401 monoclonal antibody and peroxidase immunohistochemistry we have detected IF nestin in developing and adult rat tissues. Although epitope recognized by Rat-401 antibody is relatively resistant to aldehyde fixation and paraffin embedding, the embedding of tissue samples into polyester wax and microwave antigen retrieval of histological sections enabled us to enhance sensitivity of immunohistochemical detection and to identify cells expressing low levels of nestin. Our findings confirm that nestin is predominantly distributed in developing neural, myogenic and mesenchymal cells, i.e. cell types that have been previously described to express this intermediate filament. Furthermore, we made original findings on identification of nestin expression in additional cell types, e.g. newly formed endothelial cells of extra- and intraembryonic blood vessels, epithelial cells of the developing lens, and cells apposed to hair follicles.

Key words: Dermis; Development; Endothelium; Lens; Mesenchyme; Nervous tissue; Nestin immunohistochemistry; Rat; Skeletal muscle development

\section{Introduction}

Intermediate filaments (IFs) together with microtubules, microfilaments and microtrabecules represent the major components of the cytoskeleton. Based on sequence analysis (conservation of heptad motif and spacer positions), six different classes of intermediate filaments (IFs) have been defined: acidic keratins (class I); basic keratins (class II); desmin, glial fibrillary acidic protein (GFAP), peripherin and vimentin (class III); the neurofilament triplet (class IV); nuclear lamins (class V); and nestin (class VI) - $(18,25,30)$. Postulated functions for IFs include the organization and maintenance of cell shape (17). Therefore certain IFs can be identified exclusively in certain cell types, eg. GFAP is specific for astrocytes, neurofilaments for neurons, peripherin for peripheral neurons, desmin for muscles, keratins for epithelia etc. $(5,19,25)$.

Genes encoding IFs are sequentially expressed in tightly controlled cell-type specific patterns. During development, transition from one IF protein to another occurs at major differentiation steps. Before neurulation, ectodermal cells express cytokeratins. During neural tube induction, specific type of ectodermal cells, the neuroectoderm, starts to express nestin (18). Nestin is then expressed by multipotential neuroepithelial stem cells and their progeny which gives rise to neuronal and glial cells (8). Following terminal differentiation, nestin in neuronal cells is replaced with $\alpha$-internexin $(20)$, peripherin $(19,20)$ or with neurofilaments (3) whereas in glial cells transient expression of vimentin precedes expression of GFAP which identifies fully matured astroglia (5). Another example of transition in IF expression can be seen in developing skeletal muscles: at early developmental stages, nestin is expressed in presomatic mesoderm as well in the myotome layer of the somites and then it is gradually replaced by vimentin and desmin which is specific for differentiated muscle $(18,27,29)$.

This article is devoted to immunohistochemical localization of nestin in fetal, perinatal and mature tissues using mouse monoclonal antibody (MAb) Rat-401. In agreement with observations made by other investigators, we confirm that the developing nervous tissue and skeletal muscle contain cell types that express the highest levels of nestin. Examination of histological sections of whole rat fetuses enabled us to study distribution of nestin throughout tissues. Examination of tissues taken at different developmental stages allowed us to describe a temporal pattern of nestin expression in distinct cell types. Utilization of different fixatives, embedding and pretreatment protocols as well as sensible detection systems permitted us to observe cell types that express low levels of nestin and moreover, to identify this IF in cells that have not been previously reported to be nestin-immunoreactive. 


\section{Material and Methods}

\section{Experimental animals}

All studies were performed using Wistar rats (VELAZ, Prague, Czech Republic) that were maintained under standard conditions (housed in groups of 2 rats per cage, natural day/night cycle, food and water available ad libitum). Female rats were mated with males overnight and the following day was designated as embryonic day 0 (E0). Since then, female rats had been bred separately from males. E14, E15, E18 and E19 rat fetuses were obtained after a median laparotomy carried out in deeply anaesthetized (pentobarbital $50 \mathrm{mg} / \mathrm{kg}$, i.p.) pregnant rats. At the end of surgery, pregnant rats were killed by overdose. Neonatal and postnatal rats were anaesthetized with ether and killed by decapitation. The experiments performed in this study were approved by the Animal Ethical Committee of Charles University Medical Faculty in Hradec Králové.

\section{Histology}

Rat fetuses as well as tissue blocks taken from newborn, postnatal and adult rat tissues were immersed in a neutral buffered formalin solution, $4 \%$ paraformaldehyde, $70 \%$ ethanol containing $5 \%$ acetic acid or zinc fixative $(1,2)$ for 24 $\mathrm{h}$ at room temperature. Tissue blocks were then dehydrated in increasing alcohols and embedded in polyester wax (PEW; melting point $36{ }^{\circ} \mathrm{C} ; 26$ ) or paraffin (melting point $56{ }^{\circ} \mathrm{C}$ ). Seven-micron thick coronal sections were cut from PEW and paraffin blocks and attached to the slide with poly L-lysine. Some sections were stained with haematoxylin and eosin.

\section{Immunohistochemistry}

For immunohistochemistry, all paraffin embedded sections were deparaffinized with xylene and rehydrated in decreasing ethanols to water. PEW sections were dewaxed with decreasing alcohols. Sections were incubated for 20 minutes in methanol containing $1 \% \mathrm{H}_{2} \mathrm{O}_{2}$ to reduce „endogenous peroxidase activity“. Since microwave pretreatment enables to re-establish an original conformation of epitopes modified after fixation (28), we exposed sections to microwaves in sodium citrate solution for $2 \times 5$ minutes at 700 watts. After thorough washing in $0.2 \mathrm{M}$ Tris- $\mathrm{HCl}$ buffer containing $0.5 \%$ Triton X-100 (Sigma, Prague, Czech Republic), the sections were exposed to a primary monoclonal antibody (Mab) anti-nestin (12; 1:4, clone Rat-401) for $45 \mathrm{~min}$. Rat-401 Mab was obtained from the Developmental Studies Hybridoma Bank, maintained by the Department of Pharmacology and Molecular Sciences, Johns Hopkins University School of Medicine, Baltimore, $\mathrm{MD}$, and the Department of Biological Sciences, University of Iowa, Iowa City, IA, under contract N01-HD-6-2915 from the NICHD. After thorough washing, sections were incubated with anti-mouse secondary biotinylated antibody (Sigma, Prague, Czech Republic) for $45 \mathrm{~min}$ and then with streptavidin labelled with horse radish peroxidase
(BioGenex, San Ramon, CA, USA) or alkaline phosphatase (Sigma, Prague, Czech Republic) diluted 1:100. After rinsing, the reaction was developed using DAB (3,3'-diaminobenzidine tetrahydrochloride (Sigma, Prague, Czech Republic) and hydrogen peroxide. The whole procedure was carried out at room temperature. Sections processed with omission of the primary antibody were used as controls. Sections were dehydrated, mounted in DPX (Sigma, Prague, Czech Republic), and examined by the Orthoplan light microscope (Leitz, Wien, Austria).

\section{Results}

In immunohistochemical staining Rat-401 monoclonal antibody reacted only with certain cells (e.g. radial glia, skeletal muscle, endothelial cells) whereas other structures (e.g. chondrocytes, adult connective tissue or epidermis) were completely devoid of any staining. Such a signal distribution is characteristic of a specific staining that gives no false positivity and minimum background. Omission of the primary antibody in our immunohistochemical procedure did not detect any signal revealing the fact that background and non-specific staining was kept to a minimum level. IF protein nestin was detected in all tissues irrespective of the fixation that was used. Microwave pretreatment significantly enhanced an intensity of a detected signal. When this pretreatment was applied to PEW-embedded tissue samples, the subsequent peroxidase immunohistochemistry provided a signal of the highest intensity.

\section{Nestin in neural tissues}

The neuroepithelium of fetal rats exhibited a strong and ubiquitous immunoreactivity for nestin. In E14-18 rat fetuses, intense immunopositivity was seen in cells situated in the ventricular zone, floor plate, proliferating zone as well as in radial fibres that spanned the whole thickness of the neural tube. High levels of nestin were detected in pial and perivascular endings of radial glial cells. In the fetal spinal cord, the proliferating zone contained more nestin ${ }^{+}$elements than the marginal zone (Fig. 1). In the neural tissue located outside the neural tube, IF nestin was identified in dorsal root ganglia and peripheral nerves. Ependymal cells as well as nervous cells, e.g. motoneurons and ganglionic cells were devoid of any specific labelling. In the prenatal (E19) rat CNS, nestin expression ceased in postmitotic neural elements of the cortex reflecting the fact that only few remnants of radial fibres were found; persisting nestin ${ }^{+}$ fibres were apposed to blood vessels. Nestin-immunoreactivity remained preserved in certain regions only, e.g. in the subventricular zone (SVZ), developing hippocampus, cerebellum and pial endfeet. In the SVZ, nestin was expressed in the cytoplasm of small oval cells and in slender processes of radial glia. The same pattern of distribution of nestin was observed in the neonatal (P0) CNS where only few positive profiles were seen. The highest level of nestin was expressed in the SVZ. Due to general downregulation of 


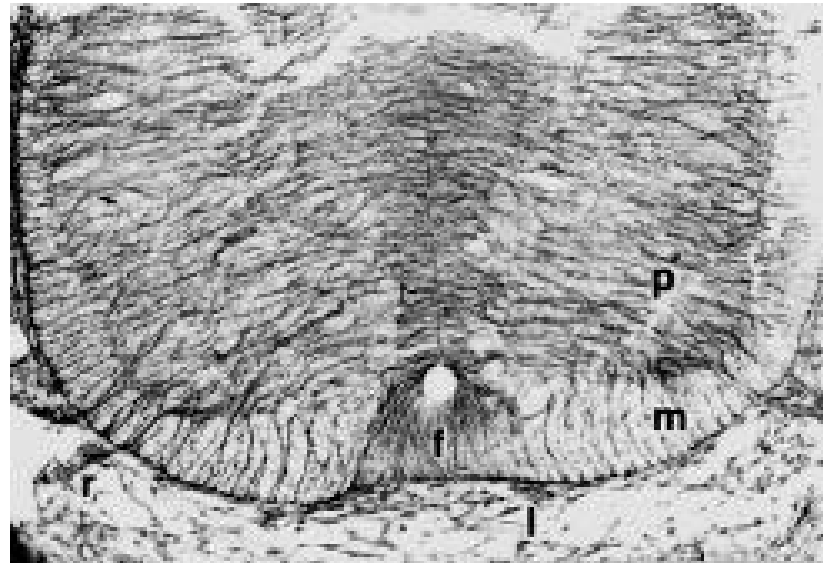

Fig. 1: In the E15 rat spinal cord, nestin was expressed by long and slim processes of radial glia cells spanning the whole thickness of the neural tube. Intense immunostaining was detected in the floor plate (f); the immunostaining was less intense in the marginal zone $(\mathrm{m})$ than in the proliferating zone (p). Outside the CNS, nestin was expressed by glial cells of the ventral roots (r) and mesenchymal cells forming the leptomeninges (1). Peroxidase immunohistochemistry, $x 90$.

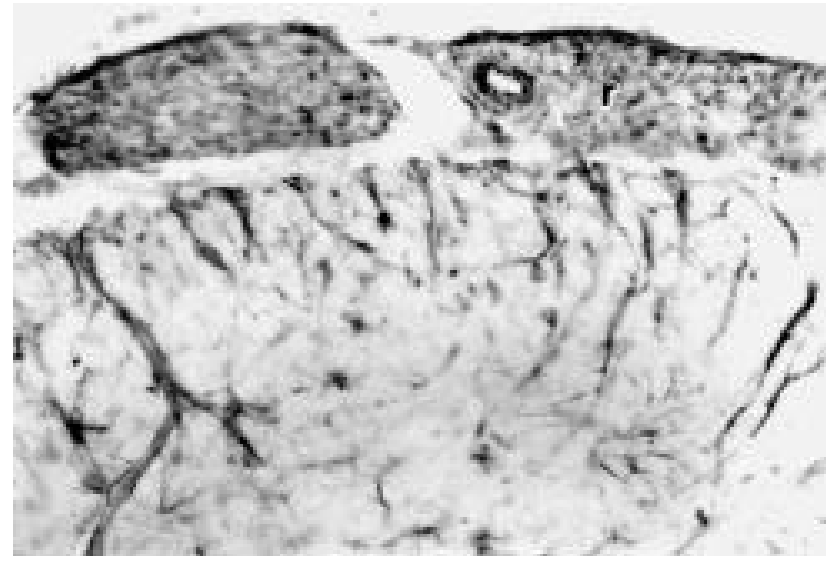

Fig. 2: In the neonatal spinal cord, nestin immunoreactivity was exhibited by endothelial cells and perivascular astrocytic endfeet. In the subarachnoid space, nestin was detected in Schwann cells of the ventral roots (r), the perineurium that enveloped peripheral nerves and accompanying blood vessels. Peroxidase immunohistochemistry, $x 225$.

nestin in surrounding neural elements, capillaries lined by nestin ${ }^{+}$endothelium became apparent (Fig. 2). In the peripheral nervous system (PNS), immunopositivity was seen in ganglia and peripheral nerves, e.g. in intercostal nerves or ventral and dorsal roots (Fig. 2). In the second and third postnatal week, IF nestin in the brain parenchyma was downregulated; relatively distinct immunostaining was seen in vascular endothelia. Completely different staining pattern was specific for brains of adult pregnant rats.
Brain surface was lined with nestin ${ }^{+}$pial endfeet forming the marginal pial membrane; nestin ${ }^{+}$perivascular endfeet were apparent in pial funnels and underlying blood vessels in the cortical molecular layer (I). Deep cortical layers (IIVI) were devoid of any immunoreactivity for nestin. Nestin immunopositivity found in deep cerebral structures, e.g. in the corpus callosum, striatum, and optic nerve, was limited mainly to fibrous astrocytes and their perivascular processes. Intense immunostaining for nestin was observed in neural precursor cells in lateral walls of the subependymal zone lining both lateral cerebral ventricles. In the wall of the lower horn of the third ventricle, antiRat-401 immunohistochemistry visualized slender processes of tanycytes. Ependymal cells did not reveal any staining. In the lesioned brain, e.g. after a suction lesion or injection of kainic acid, astrocytes became activated throughout the brain and expressed nestin. Whereas occurrence of nestin in activated astrocytes was only transient, upregulation of nestin in reactive astrocytes apposed to the lesioned area was longlasting (Fig. 3). In the PNS, non neural cells including satellite cells in dorsal root ganglia and Schwann cells in peripheral nerves were immunopositive.

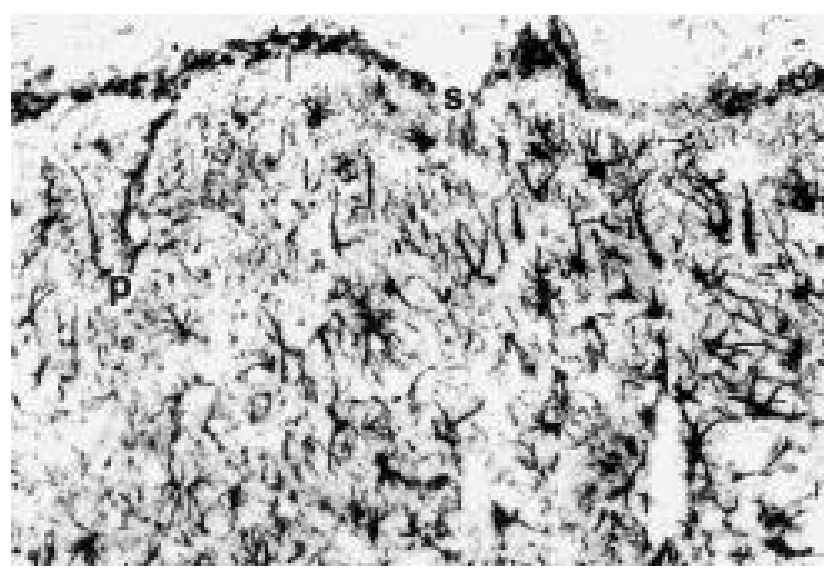

Fig. 3: Nestin immunohistochemistry revealed stellate-like reactive astrocytes that developed in the adult rat brain parenchyma that was compressed with a growing $\mathrm{C} 6$ glioma. Astroglial endfeet forming the superficial (s) and perivascular (p) limiting membranes expressed high levels of nestin. Peroxidase immunohistochemistry, $x 115$.

When we cultured dissociated cells isolated from the fetal forebrain in a chemically defined medium supplemented with epidermal growth factor that stimulates proliferation of neural precursor cells, the dividing cells formed multicellular spheroids (23). After embedding the spheroids in paraffin or PEW, cutting the sections and processing them for immunohistochemistry, we found that virtually all cells of early spheroids ( 8 days in vitro) expressed nestin. Despite all cells expressed IF nestin, 
they differed in their morphology: cells situated in the inner zone exhibited long cytoplasmic processes whereas peripheral cells possessed relatively voluminous cytoplasm and short processes (Fig. 4). Cultivation of spheroids for extended periods was accompanied with gradual differentiation of neural precursor cells into neurons, astroglia and oligodendroglia and downregulation of nestin (23).

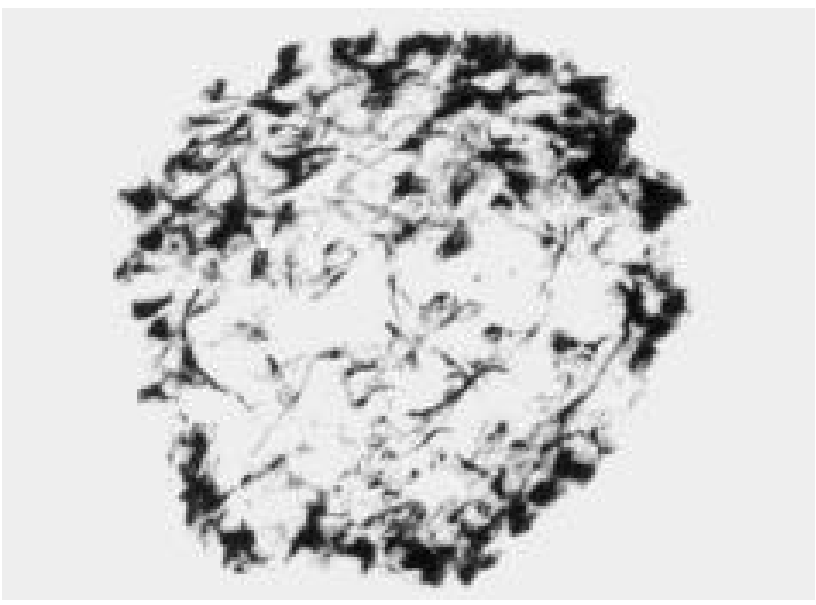

Fig. 4: Neural precursor cells forming 8-day spheroids expressed high levels of nestin. Immunohistochemistry revealed that inner cells exhibited long cellular processes whereas peripheral cells possessed short processes and voluminous, darkly stained cytoplasm. Peroxidase immunohistochemistry, $x 500$.

\section{Nestin expression in muscular tissue}

The skeletal muscle represented another source of distinct nestin immunoreactivity. Longitudinal sections of E14 rat fetuses revealed strong immunostaining of paravertebral muscles (Fig. 5). In these muscles, nestin was found in the cytoplasm of mononuclear myoblasts and exhibited a pronounced perinuclear accumulation. Centrally located nuclei of myoblasts were devoid of any staining. Myoblasts were arranged into longitudinal bands but cellular boundaries were still apparent. Transverse sections of E15 fetuses demonstrated the same pattern of nestin-immunostaining in developing muscles of the limb buds. In E18-19 rats, nestin-immunoreactivity was observed in all skeletal muscles, e.g. extraocular, pharyngeal, lingual (Fig. 6), masticatory as well as pre-, para- and postvertebral muscles. Nestin was detected in the cytoplasm of elongated myotubes that were arranged into bundles. Nestin- nuclei were still located in the centre of myotubes. A level of nestin expression slightly differed among myotubes; some of them were intensively stained whereas the others were immunostained faintly. In longitudinally-sectioned myotubes, cross-striations became apparent at these developmental stages. Neonatal (P0) skeletal muscles consisted of multinucleate muscle fibres that revealed intense nestin ${ }^{+}$ striations and nuclei displaced peripherally. Individual skeletal muscle fibres situated, e.g. in the intercostal muscle, differed again in the level of IF nestin they expressed. In adult animals, mature skeletal muscle fibres were not stained with Mab Rat-401.

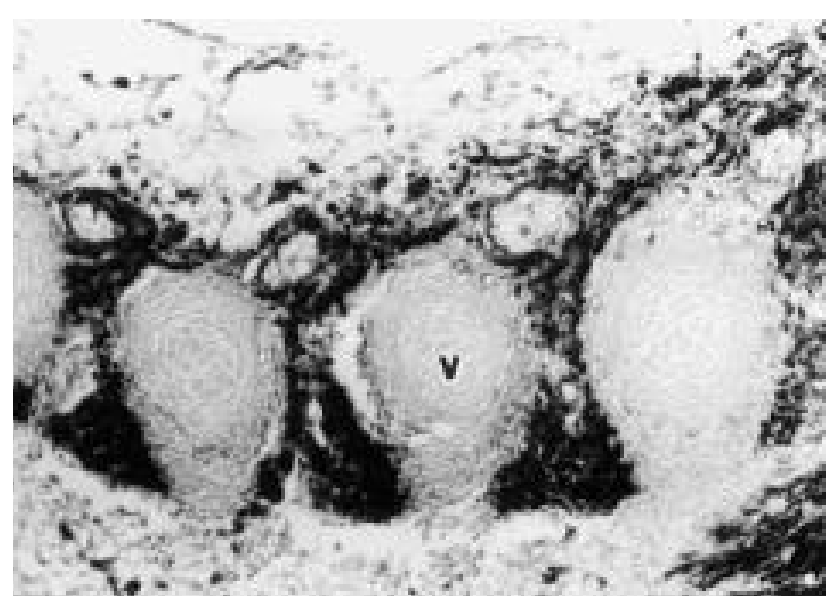

Fig. 5: Paravertebral skeletal muscles and paraxial mesenchyme of E14 rat fetuses expressed high levels of nestin. Developing vertebral bodies (v) were devoid of any staining. Peroxidase immunohistochemistry, $x 320$.

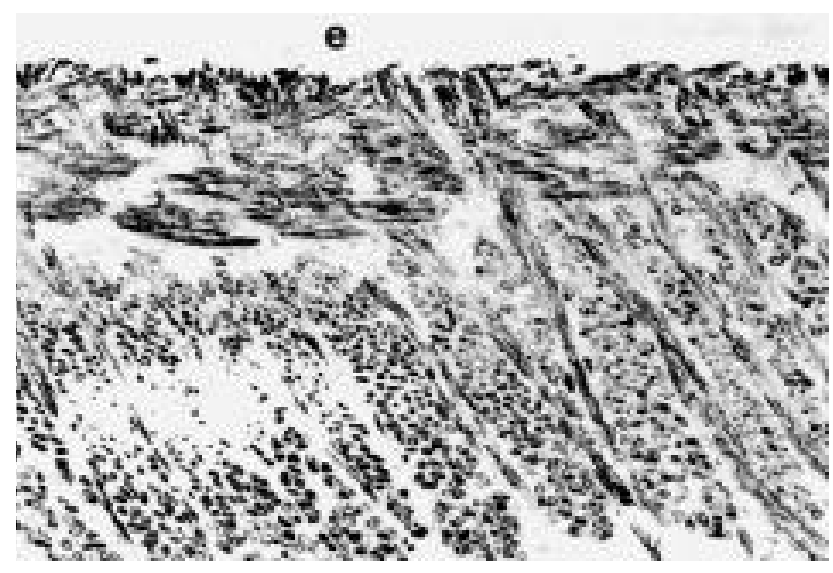

Fig. 6: Skeletal muscle of the E19 tongue. Myotubes expressed high levels of nestin; no immunoreactivity was detected in overlying stratified squamous non-keratinized epithelium (e), connective tissue and nuclei of myotubes. Peroxidase immunohistochemistry, $x 115$.

At developmental stages examined in this study (i.e. starting on day E14), no immunoreactivity for nestin was revealed in the myocardium of the developing heart. Regarding distribution of nestin in smooth muscle cells, we could observe a faint staining in cellular elements surrounding arteries and hollow organs. However, a precise identification of the cell type expressing this faint immunoreactivity requires a further analysis. 


\section{Nestin immunoreactivity of other mesenchymal elements}

Immunoreactivity for nestin was identified also in mesenchymal cells. A specific signal in the cytoplasm of these cells was lower when compared with intensity of immunostaining in developing skeletal muscles but it could be clearly distinguished from other nestin ${ }^{-}$cells, e.g. chondrocytes. Nestin $^{+}$mesenchymal cells were distributed, e.g. in the E14 paraxial mesoderm, mesonefric mesoderm, meninges, limb buds or choroid of the eye. In the course of development, nestin was downregulated in these cells. In newborn animals, nestin ${ }^{+}$cells were found in the dermis apposed to hair folicles (Fig. 7).

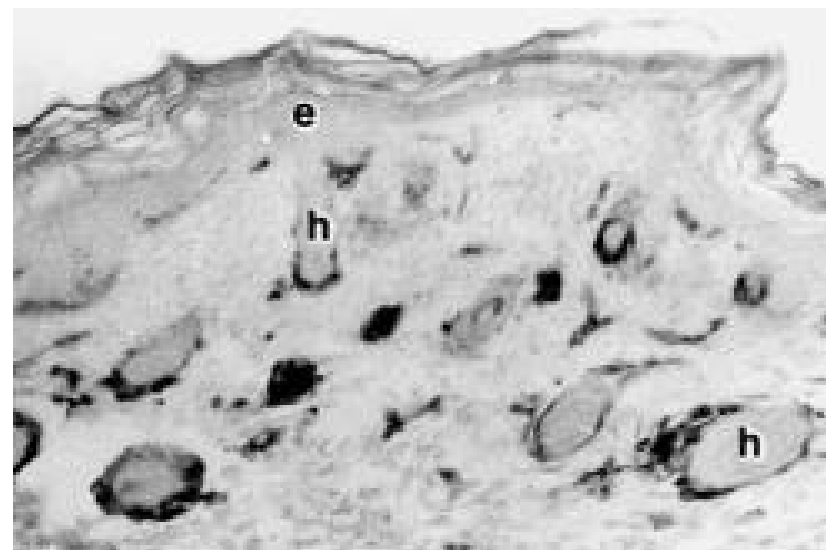

Fig. 7: In the skin of neonatal rats, no immunopositivity for nestin was observed in the epidermis (e). In the underlying dermis, nestin was expressed by vascular endothelial cells and by cells surrounding the root of hair follicles (h). Peroxidase immunohistochemistry, $x 140$.

A prominent immunoreactivity for nestin was detected in newly formed endothelial cells in both extra- and intraembryonic tissues. In extraembryonic tissues of E14 rats, nestin $^{+}$endothelial cells were observed in blood vessels of the chorion, umbilical cord and placenta. In intraembryonic tissues, endothelial cells expressing nestin were identified not only in the mesenchyme but also in organ primordia. In the E14 mesenchyme, nestin ${ }^{+}$endothelia lined capillaries running in the paraxial mesenchyme, in primitive meninges, dermis (Fig. 7), in the mesenchyme layers of the developing gut (Fig. 8), choroid of the developing eye, in the mesenchyme of limb buds. Reactivity was not confined to small blood vessels but was ubiquitous; nestin was expressed also by endothelial cells lining the largest vessels like the aorta etc. In developing organs, immunohistochemistry utilizing the anti-Rat-401 antibody identified endothelia of blood vessels supplying e.g. the forebrain, spinal cord, lung, gut, liver, spleen or heart. In the E15 heart, nestin ${ }^{+}$endothelial cells were found in capillaries supplying the myocardium as well as in endothelial cells that lined the endocardium. In $\mathrm{P} 0$ animals, nestin-immunopositivity became evident in the nervous tissue be- cause of cessation of nestin expression in neural elements. At this stage, nestin was downregulated in meningeal vessels. In the choroid plexus, endothelial and perivascular cells were labelled whereas epithelial cell were nestin-negative. Outside the CNS, nestin ${ }^{+}$endothelial cells were still present in growing organs, e.g. in the spleen, positivity was observed in sinusoids of the red pulp, in trabecular vessels, central arteries inside of malpighian corpuscles as well as in the splenic vessels situated in the hilum. Postnatally nestin expression by endothelial cells decreased; only occasional endothelial cell were immunoreactive.

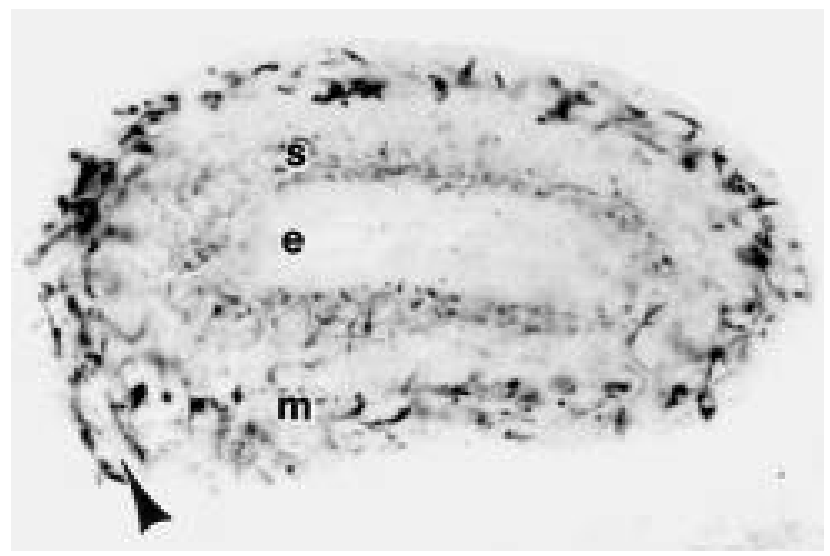

Fig. 8: In the hindgut of E14 rats, no immunoreactivity was detected in epithelium (e) covering the luminal surface. The cells expressing nestin were located in the submucosa (s) and the muscularis externa (m) layers. Nestin ${ }^{+}$cells included endothelium lining blood vessels (arrowhead) and neuroectodermal cells forming the submucosal and myenteric nervous plexuses. Peroxidase immunohistochemistry, $x 170$.

\section{Nestin expression in the developing eye}

In the developing eye, IF nestin was detected in the neural retina, lens and vascular endothelium. In E14 rats, a strong specific signal was identified in the inner thick layer of the optic cup which represents the primordium for development of the neural retina (Fig. 9). In this layer, nestin was distributed in long fibres stretching across the neuroepithelium layer (i.e. cells analogous to radial glia of the neural tube) as well as in small cellular elements; the highest levels of nestin being concentrated toward the inner surface of the optic cup. Inside the optic cup, the endothelium of the hyaloid artery and vein running through the vitreous body exhibited immunoreactivity for nestin. The lens vesicle that was situated near the edges of the optic cup also exhibited immunostaining for nestin (Fig. 9). Intense immunostaining was detected in the cytoplasm of the anterior epithelium of the lens. Nestin immunoreactivity was also expressed by cells of the posterior wall of the primitive lens. In these cells, nestin was observed in the 
cytoplasm of the cell body as well as in extremely elongated cellular processes stretching between the anterior and posterior poles of the lens and obliterating the cavity of the lens vesicle. Outside the optic cup, nestin was seen in endothelial cells lining blood vessels in the choroid. In the eye of E18 rats, faint nestin-positivity was detected in long cytoplasmatic processes of Müller cells in the retina. Strong expression of nestin was found in extraocular muscles. In the eye of adult animals, nestin-immunoreactivity was confined to fibrous astrocytes of the optic nerve and it could be distinuished starting from the area of the lamina cribrosa.

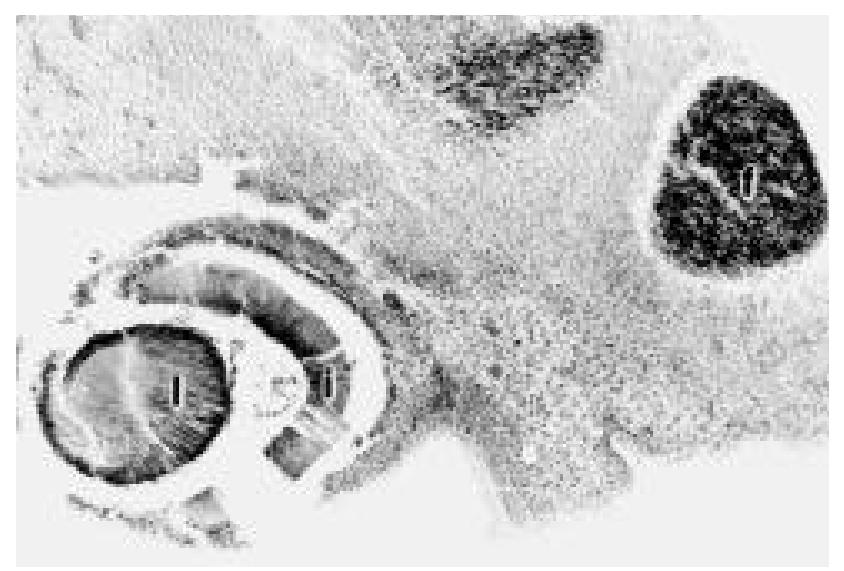

Fig. 9: In the E14 eye, nestin was expressed by cells of the inner (i) thick layer of the optic cup, epithelium of the lens vesicle (1) and choroidal blood vessels. A strong immunopositivity was observed in the neural tissue of the adjacent forebrain (f). Peroxidase immunohistochemistry, $x 50$.

\section{Discussion}

Hockfield and McKay (12) who produced Rat-401 Mab identified first cell types immunoreactive for nestin, e.g. developing skeletal muscle, radial glia, satellite and Schwann cells. A further research confirmed that nestin was abundantly expressed by developing muscles (myotomes: 16, 18, 34; myoblasts, myotubes, developing muscle fibres: 12, 27, 29; midembryonic cardiomyocytes: 15) and neural cells (neural precursor cells: 8, 18; pre-O-2A cells, $\mathrm{O}-2 \mathrm{~A}$ progenitors, pro-oligodendroblasts: 11; subependymal cells: 24 , 33; type 1 astrocytes: 11 ; reactive astrocytes: $4,9,13$; neuroectodermal tumour and glioma cell lines: 6 , 32). When anti-nestin immunohistochemistry was applied to other tissues, it appeared that immunoreactivity was not restricted to neural and muscular tissues only but was more widespread. Cells that have been found to express nestin include somites, presomitic mesoderm (34), odontoblasts (31), mesonephric mesenchyme and Sertoli cells (10) - see Table 1.
Tab. 1: Cellular distribution of intermediate filament nestin

\begin{tabular}{|c|c|}
\hline Nestin & es \\
\hline $\begin{array}{l}\text { neural precursor cells } \\
\text { radial glia cells } \\
\text { precursors of oligodendroglia } \\
\text { premitotic neuroblasts } \\
\text { reactive astrocytes } \\
\text { Schwann cells } \\
\text { satellite cells } \\
\text { developing skeletal muscle } \\
\text { developing cardiomyocytes } \\
\text { presomitic mesoderm } \\
\text { myotome } \\
\text { mesonephric mesenchyme } \\
\text { Sertoli cells } \\
\text { odontoblasts } \\
\text { newly formed endothelium } \\
\text { lens vesicle } \\
\text { gliomas }\end{array}$ & $\begin{array}{l}\text { Frederiksen and McKay, 1988; } \\
\text { Hockfield and McKay, 1985; } \\
\text { Fredericksen and McKay, 1988 } \\
\text { Gallo and Armstrong, 1995 } \\
\text { Frederiksen and McKay, } 1988 \\
\text { Clarke et al., 1994; Frisén et al., } \\
\text { 1995; Holmin et al., 1997 } \\
\text { Frisén et al., 1995; Jaeger, 1995 } \\
\text { Hockfield and McKay, 1985 } \\
\text { Hockfield and McKay, 1985; } \\
\text { Sejersen and Lendahl, 1993; } \\
\text { Sjöberg et al., 1994 } \\
\text { Kachinski et al., 1990 } \\
\text { Zimmerman et al., 1994 } \\
\text { Lendahl et al., 1990; Kachinski et al., } \\
\text { 1994; Zimmerman et al., 1994 } \\
\text { Frojdman et al., 1997 } \\
\text { Fjordman et al., 1997 } \\
\text { Terling et al., 1995 } \\
\text { Mokrý and Němeček, 1998a; 1998b } \\
\text { *This article } \\
\text { Dahlstrand et al., 1992; Tohyama } \\
\text { et al., 1992 }\end{array}$ \\
\hline
\end{tabular}

Utilization of sensitive immunohistochemical detection systems, e.g. labelled streptavidin-biotin, enabled to identify lower amounts of IF nestin than two-step indirect methods used in the first studies. A further increase in sensitivity of anti-nestin immunohistochemistry was reached by embedding tissue samples in low melting medium (e.g. PEW), cutting thin sections, suppression of non-specific background staining, permeabilization of sections with detergents and microwave antigen retrieval. Combination of these approaches allowed us to confirm previous findings made by other authors and give a clear evidence of nestin expression by endothelial cells of extra- and intraembryonic blood vessels $(21,22)$. Application of this detection method to sections of whole rat fetuses enabled us to localize nestin in other cells that have not been previously described to express nestin, e.g. in the epithelium of the developing lens.

Most developing cells, that have been found to contain protein nestin, express this IF only for a limited period of their development. A transient expression of nestin has been thoroughly described in the developing CNS $(8,12$, 18). The onset of nestin expression in the rat brain was first detected in pial end foot on E10. Its level rapidly increased and on E12 all neuroepithelial cells expressed nestin. Fredericksen and McKay demonstrated that nestin expression occured mainly in proliferating neural cells (8). Maximum nestin expression in the cerebrum was detected on day E16 whereas in the cerebellum on P5 (18). The loss of nestin expression coincided with terminal differentiation of NPCs. In agreement with this observation, we detected low levels of nestin in P14 forebrains and almost none in the adult cerebral cortex. Transient expression of nestin has 
been described also in other cell types, e.g. in cardiomyocytes, developing skeletal muscle, mesenchymal cells, neural cells, endothelial cells (e.g. 8,12,14,15,18,21,22,27,29,34).

After these nestin ${ }^{+}$cell types, undergo their terminal differentiation, nestin is downregulated and replaced with another type of IF, eg. $\alpha$-internexin (20), neurofilaments (3), or peripherin $(19,20)$ in nervous cells, vimentin and glial fibrillary acidic protein in astroglia (5) or vimentin and desmin in myogenic cells $(27,29)$. Actually in these cell types nestin is not abruptly downregulated but is co-expressed with another IF (e.g. GFAP, vimentin, neurofilaments, desmin) for a transient period of development $(20,29)$. Nestin has been reported to copolymerize with other IFs, e.g. with vimentin and GFAP (20).

Possible role of IF nestin must be associated with maintenance of transient functions of undifferentiated cells, e.g. their proliferation and migration. The cytoskeleton of endothelia in developing vessels must permit mitotic divisions of endothelial cells and their movement towards primordia of avascular organs. It is likely that the presence of nestin in the cytoskeleton confers on the endothelial cell a necessary flexibility and elasticity that is required for performance of these funcions (i.e. cellular division and migration). After the cells mature, they stop to divide and move, and then establish definitive junctions with neighbouring resting endothelial cells which is accompanied with reconstruction of their cytoskeleton and loss of immunoreactivity for nestin. A possible role of class VI IF nestin in the epithelial cells of the developing lens may be linked with formation of extremely elongated lens fibres. Nestin has been demonstrated to participate in forming a structure of other extremely long fibres, e.g. in radial glia $(8,12)$ and odontoblasts (31). After the columnar epithelial cells of the developing lens differentiate, they form junctions with other fibres, lose their nuclei and other organelles and stop to express IF nestin.

\section{Acknowledgement}

Authors are grateful to Mrs. Hollerová and Hetešová for technical assistance and Dr. J. Ourednik, Swiss Federal Institute of Technology, Zurych, for providing protocols for embedding in PEW and PEW embedding medium. Supported by a grant No. 304/97/1117 from the Grant Agency of the Czech Republic.

\section{References}

1. Beckstead JH. A simple technique for preservation of fixation-sensitive antigens in paraffin-embedded tissues. J Histochem Cytochem 1994;42:1127-34.

2. Beckstead JH. A simple technique for preservation of fixation-sensitive antigens in paraffin-embedded tissues: Addendum. J Histochem Cytochem 1995;43:345.

3. Cattaneo E, McKay R. Proliferation and differentiation of neuronal stem cells regulated by nerve growth factor. Nature 1990;347:762-5.
4. Clarke SR, Shetty AK, Bradley JL, Turner DA. Reactive astrocytes express the embryonic intermediate neurofilament nestin. NeuroReport 1994;5:1885-8.

5. Dahl D. The vimentin-GFAP protein transition in rat neuroglia cytoskeleton occurs at the time of myelination. J Neurosci Res 1981;6:741-8.

6. Dahlstrand J, Collins VP, Lendahl U. Expression of the class VI intermediate filament nestin in human central nervous system tumors. Cancer Res 1992;52:5334-41.

7. Fraichard A, Chassande O, Bilbaut G, Dehay C, Savatier $\mathrm{P}$, Samarut J. In vitro differentiation of embryonic stem cells into glial cells and functional neurons. J Cell Sci 1995; 108:318-8.

8. Frederiksen K, McKay RDG. Proliferation and differentiation of rat neuroepithelial precursor cells in vivo. J Neurosci 1988;8:1144-51.

9. Frisén J., Johansson CB, Török C, Risling M, Lendahl U. Rapid, widespread, and lonlasting induction of nestin contributes to the generation of glial scar tissue after CNS injury. J Cell Biol 1995;131:453-64.

10. Frojdman K, Pellieniemi LJ, Lendahl U, Virtanen I, Eriksson JE. The intermediate filament protein nestin occurs transiently in differentiating testis of rat and mouse. Differentiation 1997;61:243-9.

11. Gallo V, Armstrong RC. Developmental and growth factor-induced regulation of nestin in oligodendrocyte lineage cells. J Neurosci 1995; 15:394-406.

12. Hockfield S, McKay RDG. Identification of major cell classes in the developing mammalian nervous system. J Neurosci 1985;5:3310-28.

13. Holmin S, Almqvist P, Lendahl U, Mathiesen T. Adult nestin-expressing subependymal cells differentiate to astrocytes in response to brain injury. Eur J Neurosci 1997;9:6575.

14. Jaeger CB. Isolation of enteric ganglia from the myenteric plexus of adult rats. J Neural Transplant Plast 1995;5:223-32.

15. Kachinsky AM, Dominov JA, Miller JB. Intermediate filaments in cardiac myogenesis: Nestin in the developing mouse heart. J Histochem Cytochem 1995;43:843-7.

16. Kachinsky AM, Dominov JA, Miller JB. Myogenesis and the intermediate filament protein, nestin. Dev Biol 1994; 165:216-28.

17. Lazarides E. Intermediate filaments as mechanical integraters of cellular space. Nature 1980;282:249-56.

18. Lendahl U, Zimmerman LB, McKay RDG. CNS stem cells express a new class of intermediate filament protein. Cell 1990;60:585-95.

19. Leonard DGB, Gorham JD, Cole P, Greene LA, Ziff EB. A nerve growth factor-regulated messenger RNA encodes a new intermediate filament protein. J Cell Biol 1988;106:181-93.

20. Liem RKH. Molecular biology of neuronal intermediate filaments. Curr Opin Cell Biol 1993;5:12-16.

21. Mokrý J, Němeček S. Angiogenesis of extra- and intraembryonic blood vessels is associated with expression of 
nestin in endothelial cells. Folia Biol (Prague) 1998a; in press.

22. Mokrý J, Němeček S. 1998b, unpublished results.

23. Mokrý J, Šubrtová D, Němeček S. Differentiation of epidermal growth factor-responsive neural precursor cells within neurospheres. Acta Medica (Hradec Králové) 1996;39:7-20.

24. Morshead CM, Reynolds BA, Craig CG, McBurney MW, Staines WA, Morassutti D, Weiss S, van der Kooy D. Neural Stem Cells in the adult mammalian forebrain: A relatively quiescent subpopulation of subependymal cells. Neuron 1994;13:1071-82.

25. Nagle RB. Intermediate filaments: A review of the basic biology. Am J Surg 1988;12:4-16.

26. Ourednik J, Ourednik W. Preservation of the structural integrity of a freshly lesioned or transplanted mouse neocortex and the immunoreactivity of cell-specific marker proteins in demineralized histological material. J Neurosci Meth 1995;62:55-63.

27. Sejersen T, Lendahl U. Transient expression of the intermediate filament nestin during skeletal muscle development. J Cell Sci 1993;106:1291-300.

28. Shi SR, Key ME, Kalra KL. Antigen retrieval in formalin-fixed, paraffin-embedded tissues: An enhancement method for immunohistochemical staining based on microwave oven heating of tissue sections. J Histochem Cytochem 1991;39:741-8.

29. Sjöberg G, Jiang WQ, Ringertz NR, Lendahl U, Sejersen T. Colocalization of nestin and vimentin/desmin in skeletal muscle cells demonstrated by three-dimensional fluorescence digital imaging microscopy. Exp Cell Res 1994;214:447-58.

30. Steinert PM, Roop DR. Molecular and cellular biology of intermediate filaments. Annu Rev Biochem 1988;57:593625 .

31. Terling C, Rass A, Mitsiadis TA, Fried K, Lendahl U, Wroblewski J. Expression of the intermediate filament nestin during rodent tooth development. Int $\mathrm{J}$ Dev Biol 1995;39:947-56.

32. Tohyama T, Lee VM-Y, Rorke LB, Marvin M, McKay RDG, Trojanowski JQ. Nestin expression in embryonic human neuroepithelium and in human neuroepithelial tumor cells. Lab Invest 1992;66:303-13.

33. Zerlin M, Levison SW, Goldman JE. Early patterns of migration, morphogenesis, and intermediate filament expression of subventricular zone cells in the postnatal rat forebrain. J Neurosci 1995;15:7238-49.

34. Zimmerman L., Lendahl U, Cunningham $\mathbf{M}$ et al. Independent regulatory elements in the nestin gene direct transgene expression to neural stem cells or muscle precursors. Neuron 1994;12:11-24.

Submitted April 1998

Accepted May 1998.

MUDr. Jaroslav Mokrý, Department of Histology and Embryology, Charles University, Faculty of Medicine, Šimkova 870, 50001 Hradec Králové, Czech Republic. 